\title{
To the editors of the Philosophical Magazine
}

\section{G. Quincke}

To cite this article: G. Quincke (1898) To the editors of the Philosophical Magazine , Philosophical Magazine Series 5, 46:283, 572-572, DOI: 10.1080/14786449808621237

To link to this article: http://dx.doi.org/10.1080/14786449808621237

曲 Published online: 08 May 2009.

Submit your article to this journal

Џ Article views: 2

Q View related articles $₫$ 
2. Models of the kind described may therefore likewise belong to either of two classes-one cunstructed with wheels whose teeth form left-handed screws; the other with wheels whose teeth are right-handed.

3. The properties of models of the two kinds are, when considered ear,h by itself, identical; but relatively to each other they exhibit symmetrical inversion.

4. On attempting to combine a constituent of one of the above classes with one of the other class, it is found that it is possible to make them gear into each other only when their axes of revolution are parallel. Such a combination of helical-toothed gearing with parallel axes has a similar property to a combination with axes at right angles (the separate wheels being consequently of the same kind): a limited positive or negative acceleration of the rotation of one of them causes the rotatory motion of both to be partially transformed into motion of translation : the wheels move in opposite directions along their axes of rotation until the acceleration ceases or is replaced by one of opposite sign, and so on (vid. Phil. Mag. loc. cit.).

5. By combining with each other in different ways pairs of righthanded and pairs of left-handed helical-toothed wheels (thus forming at the same time one or more of the pairs mentioned in the last paragraph), various closer combinations can be made, each of which is distinguishable from the rest, and can in turn serve, as a unit of a higher order, for building up a wheel-model with a regular distribution in space, and with the described properties of transforming rotatory motion into motion of translation.

6. The number of possible models of this latter kind is, in general, dependent upon the number of elements which go to the formation of their constituents,-the more numerous these are, the longer in each case is the series of the possible resulting combinations.

Degerloch (Würtemberg), November 4th, 1898.

To the Editors of the Philosophical Magazine.

\section{Genthemen,}

Is the May number of this Magazine (pp. 432-447) Mr. A. P. Wills has described a method of measuring with the balance the susceptibility of diamagnetic and feebly magnetic substances. I venture to point out that the same method was described by me so long ago as 1839 (Tageblatt der 62 Versammlung deutscher Naturforscher und Aerzte in Heidelberg, pp. 209-211), as used for measuring the magnetic constants of Iron, Nickel, Cobalt, Oxide of Iron and Bismuth, parallel and perpendicular to the lines of magnetic force. The method effects for solids precisely what the method I have given of measuring magnetic forces by means of hydrostatic pressure does for liquids (Wiedemann's Annalen, xxiv. pp. 347-416, 1885), and has for ten years past been repeatedly used in my Laboratory here, as for instance by Herr Paul Meyer (Dissertation, Heidelberg, 1889 ; Electrotechnische Zeitschrift, x. pp. 582-587); Max Weber (Wiedemann's Annalen, liv. pp. 30-43, 1895), and Ernst Seckelson (Dissertation, Heidelberg, 1898).

University of Heidelberg.

Physical Laboratory,

November 7,1898
Very faithfully yours, G. QUINOKE. 